\title{
Learning in large learning spaces: the academic engagement of a diverse group of students
}

\section{Clive Hunt}

\author{
School of Design, Engineering and Computing, Bournemouth University, \\ Bournemouth, UK
}

To cite this article: Hunt, C. 2012. Learning in large learning spaces: the academic engagement of a diverse group of students, Research in Post-Compulsory Education, 17:2, 195-205

To link to this article: http://dx.doi.org/10.1080/13596748.2011.626983

\begin{abstract}
Teaching larger groups of students is a growing phenomenon in HE and this brings with it, its own challenges not least for the students themselves but also their lecturers. Demographic factors as well as the experiences that characterise us as individuals will impact upon our ability to learn. The pilot study reported here considered the "academic engagement" of a diverse group of students where their course is delivered in large learning environments. As a pilot study, the paper concludes with the identification of two areas which are worthy of further research. Firstly, the study highlighted that mature students were more likely to engage in learning strategies that are associated with surface learning - the binary opposite to which practitioners often strive to achieve. Secondly, the research suggests that students who appear to know their tutors well indicate a preference for study approaches that are likely to develop deeper learning.
\end{abstract}

Keywords: academic engagement, surface learning, engaged, disengaged, deep learning, large groups, post-compulsory education

\section{Introduction}

Following neo-liberalism as a dominant political paradigm, which has contributed to economic globalisation pressures, entrepreneurial demands have been put on higher education institutions across the world which has led to internal restructuring of institutions. For many universities, this has formed the incentive structure for them to recast their position. Midway University, the alias used to describe a post-92 university and within which the research for this paper was undertaken, is set on moving from a teaching led university to one which is academically led. In its corporate plan the University forecast the extreme competitive environment that the future holds and considers the need to make more efficient use of its academic staff resource. Represented and imagined in Midway University's institutional policy discourse is the idea of the "academic" versus the "teacher", where academics bring together their teaching and research and teachers focus on pedagogic activities.

The pilot study reported upon here relates to the freeing up of teaching related activities as the work balance of academic staff shifts from one which was predominantly teaching focussed to one now that also includes research, enterprise and professional practice. The aim of this paper is to consider "academic engagement" of a diverse group of students where most of their units are delivered in "large learning environments". This follows Midway's policy decision to develop "frameworks" of programmes for the delivery of undergraduate and postgraduate taught pathways within all of its disciplines. Prior to the restructuring of academic 
activities, courses were mostly delivered as individual holistic programmes of relatively small numbers of students (around 40 to 50) and often seminars were replicated by staff on a number of occasions in groups of about 15 students. Following the restructuring, it is no longer uncommon for students to attend lecture theatres having capacities of almost 250 and computing "super labs" which seat more than 50 students. The move to teaching students in larger numbers is not a new phenomenon in HE, as Agnew and Elton (1998) observe, large group sessions are used in higher education as a means of enabling academic staff to make more effective use of their time. This clearly aligns with Midway University's desire to make more efficient use of its teaching staff resource.

The study being reported upon here considers the delivery of courses that form Midway's BSc (Hons) Computing Framework. In particular, the focus of the project is to gain an understanding of whether student diversity is considered by academics who teach large groups of students. The report does not reflect upon how to teach, or the various learning strategies that might be adopted, but poses the question of whether the teaching of a large, diverse group of undergraduates in a single group can be genuinely inclusive?

Before continuing and to provide a starting point, it is appropriate to provide descriptors of what is meant by the terminology described in the paper.

Hockings et al $(2010,95)$ define what they mean by "academic engagement" from a synthesis of the work of others in relation to learning and knowledge. Their definition, which forms the focus of this paper, is that academic engagement is either "engaged" or "disengaged", that is, "deep" or "surface". They comment that:

When students are academically engaged they adopt a 'deep' approach to learning (questioning, conjecturing, evaluating, making connections between ideas), and draw on their own and others' knowledge and experiences, backgrounds and identities in coming to know and understand. They often appear animated and animate others.

When students are disengaged they adopt a 'surface' approach to learning (copying notes, memorising or focussing on fragmented facts and right answers, jumping to conclusions, accepting) and keep academic subject knowledge and knowing separate from personal knowledge and knowing, background and experiences. They may also appear distant or isolated, distracted by or distracting to others. (Hockings et al 2010, 96)

Trigwell et al $(1999,67)$ express a view that a deep approach to learning is more likely to take place if lecturers' take a student focused approach, that is, students are, "the focus of their activities" and places an emphasis on "what the student is doing and learning", rather than what is being covered. Lea, et al $(2003,322)$ assert that there is, "an emphasis on deep learning and understanding" when a student centered learning approach is adopted. It is important to note, that "deep learning" and "surface learning" are not traits of individuals, but descriptors used in considering the student learning experience (Hockings et al 2009, 96). Marton and Säljö (1984, 57) suggest that students who focus attention upon and draw meaning from their learning with consideration to the "real world" take a deep approach to learning. All of these perspectives, however, are simplistic generalisations and may not reflect reality as they do not take into account "differences in learning orientations" (Ramburuth 2001, 3 ) or "prior learning and cultural influences" of students (4). A number of researchers including Colley et al $(2003,476)$ identify learning as being "determined in part by the dominant structures", the "epistemological assumptions of their different disciplines" (Neumann et al 2002 cited by Norton et al 2005, 553), and the 
"communities of professional or vocational practice associated with them" (Hockings, et al 2010, 101).

Since this paper reflects upon the academic engagement of students in what might be termed as "large learning environments", it is now time to consider the term "large" as a dimension to the study. Grace and Gravestock (2009) assert that it is not possible to differentiate what constitutes a "small" or a "large" group of students and suggest that the difference should really be related to how sessions are facilitated:

[...] in small-group teaching the lecturer will often be acting as a facilitator of discussions, whereas in large-group teaching there is likely to be more focus on the lecturer initiating and providing discussions about a particular theme. This is not to say that the role of the lecturer in large-group teaching is to 'deliver' material, nor that the students should be passive recipients of information, and we would encourage the use of interactive lectures. (Grace and Gravestock 2009, 79)

What Grace and Gravestock identify might be considered as problematic. On the one hand, it seems, they believe it is not possible to differentiate between large and small groups, but on the other they point out that lecturers will approach things differently depending upon group size. Clearly, however, as the numbers of students increase in a given learning environment, the likelihood of diversity and preference in learning styles will also increase. A better measure, therefore, of what is a small or large group may come from the students and lecturers' themselves when they encounter particular learning spaces.

Finally, before moving to the methodology used, the term "diversity in higher education" needs to be positioned. On the one hand, Trow (1995), cited by Meek, et al $(2000,3)$ offers this as being "the existence of distinct forms of post-secondary education, of institutions and groups of institutions" which have "different and distinctive missions" and as Brown $(2000,4)$ advises is at "institutional level". Others, however, including Bowl, et al $(2008,11)$ use the term in a different context and identify that diversity in higher education includes an, "individuals' prior educational experiences, aspirations and motivations for studying", as well as "structural factors such as class, gender, age and ethnicity". For the purposes of the research reported upon in this paper it is their definition, relating to differences of individual students, that has been adopted.

Researching the link between student diversity and the academic engagement of the student is important. In the midst of a period which might be described as the massification of HE, university teachers across the UK and indeed the world, are being faced with larger learning environments in which to deliver their units. Plainly, with the political drive to widen access to $\mathrm{HE}$ in the UK, student diversity and differentiation in entry level skills are likely to increase. It is crucial, therefore, that the learning needs of students will continue to be met.

\section{Methodology}

Consideration to a variety of approaches that are available from interpretivist and positivist paradigms was given. From a pragmatic perspective, within the constraints of the resource available, a mixed methods approach was adopted. From a qualitative perspective semi-structured interviews and a focus group was employed. These were complemented by quantitative data collection and analysis in the form of an online questionnaire. Participants were drawn from staff and students from Midway University's undergraduate computing framework at Level C [in the UK, the first year 
of an undergraduate programme is commonly referred to as level C]. This methodology provided a deep understanding of the actions of learning and provided a means of triangulation.

The one to one, semi-structured interviews took place with three white British female members of academic staff who each teach different subjects on the course at level C. Following an invitation to participate in the study the three female lecturers were the only members of staff, from a group of three male and four female academics, that volunteered. The staff interviews were used to determine the views of academics on issues relating to teaching diverse student groups in large lecture theatres and computing super-labs, with a particular focus on learning and teaching strategies.

The student focus group, which comprised of seven first year students that were recruited from an initial enrolment of almost 200, was used as a means to explore the student learning experience. A semi-structured approach was adopted to enable the students to discuss shared and opposing views as well as guiding the discussion. The student participants were recruited following a brief presentation by the researcher at one of their last lectures of the academic year. Around five minutes at the beginning of the lecture period was used by the researcher to explain the purpose of the research being carried out with the aim of enabling students to put a "face to a name" when the eventual questionnaires were sent out. It was hoped that this strategy would prove useful in helping to secure an improved response rate when an email was sent to every level $\mathrm{C}$ student in the framework requesting volunteers to come forward and to encourage all of them to participate in the questionnaire that was to follow. It became apparent that the student volunteers were representative of the diverse mix of students enrolled on the course, but not in proportionate numbers. The group consisted of six male students and one female student. Two of the students were over 21, though one was significantly older and with specific learning needs and two were from overseas. Both state and public schools were represented by the home as well as the overseas students.

The staff interviews and the student focus group each lasted approximately one hour, and with the signed permission of each of the participants they were audiotaped. Confidentiality and anonymity was assured by the use of a research consent form.

A conceptual framework for the questionnaire was constructed from the thematic content analysis of the staff interviews and the student focus group, as well as a review of relevant literature concerning "approaches to studying" (Richardson 2005, 675). It broadly covered areas such as demographics, individual diversity including external factors that might affect depth of academic engagement such as a commitment to paid employment and learning strategies that are associated with deep and surface learning. An initial draft of the proposed online questionnaire, consisting of twenty four items and designed to take a structured approach, was formulated to seek the views of the entire cohort of first year computing students. The questionnaire was piloted with eight students from a different undergraduate framework, at the same institution, prior to the questionnaire going live. Participants in the pilot were asked to consider the clarity of questioning, the time taken and the ease by which questions were completed. This exercise proved invaluable. It became clear that some questions were framed wrongly and others were inappropriate, in terms of the construct being measured. Questions that were framed wrongly were reworded, and those questions that appeared to be inappropriate, in terms of that being measured, were reviewed against the types of questioning used in other research 
projects that also investigated academic engagement, namely those of Lea et al (2003) and Thomas, et al (2000). The final edited version of the questionnaire consisted of twenty one items and was sent via email to respondents during the first week of their long summer vacation requesting that they respond within three weeks.

Unfortunately, due to time constraints, testing the reliability of the survey through the use of a " "test - retest' procedure" was not possible (Bush 2007, 92). In terms of validity, the use of questionnaires is considered to be problematic from two angles (Belson 1986 in Cohen, et al 2007, 157). Firstly, there is an issue of noncompletion, and whether those who did not return the questionnaire would have provided similar responses to those that did. Secondly, it is possible that those who did return a response may not have understood the questions and/or may not have provided honest responses. As already mentioned, attempts were made to maximise the response rate to the questionnaire.

For the interviews and focus group Cohen, et al $(2007,150)$ suggests that, "the most practical way of achieving greater validity is to minimise the amount of bias". They recognise, however, that for unstructured and semi-structured interviews this will be difficult to avert and is a function of the interviewers own bias, their training and the bias of the respondents themselves. Reliability, on the other hand, can be controlled by having, "a highly structured interview" (Cohen, et al 2007, 150) but undoubtedly this would impact upon the respondents' view of the world and rich data would most likely be lost. As previously mentioned, for this study the interviews and focus group followed a semi-structured approach based upon a framework relating to different "approaches to studying" so as to document variations and common patterns.

\section{Findings - Qualitative Data}

To compare and derive categories for exploration in the student questionnaire, the audio taped data derived from the individual staff interviews and the student focus group were coded as a means to identify emerging themes. Generally, there was agreement between categories.

Staff had a clear understanding of why Midway University moved to deliver units in large groups, as part of discipline focussed frameworks. They believed it to be the reality of a wider policy context aimed at promoting academics' work to include higher levels of research and to increase academic activity with no real increase in resource. The following quote from a member of staff asserts this:

I have to produce research; therefore, they need to give me more time to do that. If I have less contact time with the students then I can do more, and because of that if you have bigger sizes of classes you can reduce the number of hours which will give me more time to do research. (Academic staff 1)

Students, however, did not identify with the idea of the academic versus the teacher but simply considered that the teaching of large groups was to save money.

The data suggests a difference of opinion between staff and students in terms of what is a small or large group, but both recognised that the appropriate number of people taking part in a shared learning experience is a function of whether it is a lecture, a seminar or a lab. For students, lecture group sizes or more than 30 was considered to be large whereas the lecturers identify a limit to be around 60 or 70 . These maximum limits seem to be based upon their individual cognitive perception, that is, they appear to assess their own educational experiences and deduce an upper limit based upon it. Academic staff provided a ceiling on student numbers based upon lecture groups that they delivered before their units were put into common 
frameworks. The students, who were in their first year, appeared to provide an upper limit based on their experience at school.

Academics and students recognised that there is a reduced dialogue taking place in lecture theatres and the computing super lab. Student numbers in excess of 70 were considered to be impractical if discussion between the lecturer and students was to take place. The following encapsulates the general feeling:

With 60 to 70 students you could get students to talk to you . . . with 200 students they don't interact at all. (Academic 2)

If you've got 200 people on the course ... you can't have a discourse with the lecturer. (Student 1)

There is a back of the class mentality ... you have to concentrate a lot harder, it can really affect you. That's why I tend to work from home for my super lab sessions (Student 4).

Students as well as academic staff appear to accept that for the future, increasing numbers of students will participate in lectures and consider this as a done deal. For example, one student said:

There is no getting away from having 200 people in a lecture theatre. It's just gonna have to happen. (Student 4)

The importance of getting to know students as individuals was highlighted by staff and they identified that seminars and lab sessions were the fora in which this could take place. Academics as well as students cited the ideal class size for these sessions to be around 20. Seminars were used for reviewing lectures, asking questions, practising computer skills and where staff and students could get to know each other. As one lecturer put it:

The worst problem is that I used to know all my students by name. If I had a conversation with another member of staff, I could say 'Oh, so and so has got some problems at the moment and we need to just keep an eye on it'. We could have that conversation now, but we wouldn't know who the students are. (Academic 1)

The interviews clearly identified that both sets of respondents consider that Midway's computer super lab, which seats over 50 students did not aid learning. The following were typical comments:

With 18 students, if you were wandering around a lab you talked to students and built up a rapport - you could see what each student was doing. So actually what you are doing is as you go around the lab is noting who they are and who's got problems and who needs help. But when it's in a space of 54 you can't do that. (Academic 1)

It was a timetabled session with a least 60 or 70 odd in one room. There was one head lecturer and a few other helpers. . I I remember Reham [alias] ripping her hair out over being sat there and wanting help and not receiving help for over an hour. That's an hour of her time wasted because she could not progress until she had her question answered... We have seminar sessions of 
around about 20; those are usually productive, usually very productive. (Student 1)

In its broadest sense, staff identified with the term "diversity", and assumed its meaning to be broadly the same as that adopted for this paper. One member of staff explained:

I expect my class to have some high achievers; some people will be stumbling along at the bottom. They [the students] could be any race, colour, creed, they could be non-dyslexic, dyslexic, blind - they are all the same. They're students and you've got to get them from $\mathrm{A}$ to $\mathrm{Z}$ somehow. (Academic 1)

Of the staff interviewed, it was apparent that they adopted pedagogical strategies which were intended to cater for the diversity of students in the class. One of the interviewees talked about the interventions that she had used to engage her students:

I have lectures and seminars. My seminars are mostly about student discussion. I make them [students] take charge of what they are doing, it's not about me it's about them learning and that's how I always work. In lectures, I use all sorts of things, I use podcasts, I use films and things that students have found out themselves. (Academic 1)

Staff clearly recognised the terms deep and surface learning. For a student to engage in deep learning they expected students to have an understanding in terms of context and implications of writing program code. One of the teachers suggested that students who had gained a deep approach to learning would have "moved through layers". She also believed that too many students wanted to reproduce what she had said and to "reconstruct it enough to get a pass". She described this as "surface learning".

As a product of large class sizes, staff did not appear confident in determining the level of engagement of individual students. One of the academics suggested that engagement with learning was the responsibility of the student:

Students have to understand the reason for what they are doing and be able to think their way through why it might be useful. (Academic 1)

This lecturer did believe, however, that student academic engagement had improved but thought that this was not related to her teaching methods but to the "standard of student we are getting". Norton, et al $(2005,559)$ point out, however, that women are "likely to hold a conception of teaching as learning facilitation" this suggests that her approach may be promoting the intellectual development of her students.

\section{Findings - Quantitative Data}

A total of 189 students were asked to complete the online questionnaire, of which $20 \%$ (38) responded. The demographics which follow indicate the diversity of the student cohort being reported upon. The majority of respondents were male (79\%) and $61 \%$ were aged under $21.82 \%$ of respondents considered themselves to be white British. $21 \%$ reported that they had Additional Learning Needs (ALN). Just over half 
of the respondents lived in University accommodation and $83 \%$ went to UK state schools. $58 \%$ of the students entered university with A-levels of which the average UCAS tariff points at A2 was equivalent to BBC grades. The parents for the majority of students $(78 \%)$ had not gone to university and for $58 \%$ of students they were the first in their family to have experienced HE. Almost half $(46 \%)$ attended lectures/seminar for less than $80 \%$ of the time. At one extreme, most students $(77 \%)$ did not have paid employment whilst at University whereas, one student reported having more than 24 hours of paid work.

From a randomised list of ten approaches to studying that are considered in many literary sources to be traits of academic engagement, respondents were asked to rank five of the approaches that they considered were most applicable to them. Table 1 indicates the percentage of respondents who indicated a preference for each learning approach. Considering a cohort of a large number of students, these statistics are important as it has signalled the possibility of there being many different preferred approaches to learning that will exist within a large teaching group. Pedagogies need, therefore, to "take account of the diversity within the classrooms and address individual needs" (Hockings, et al 2010, 107).

\begin{tabular}{|c|c|c|c|}
\hline & Responses to various approaches to studying & $\begin{array}{l}\% \text { agree } \\
\text { with }\end{array}$ & \multirow{6}{*}{ 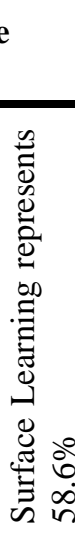 } \\
\hline S & I like to copy notes and/or memorise what is being said & 15.2 & \\
\hline S & I like to focus on facts & 13.8 & \\
\hline S & I regularly accept what the lecturer tells me & 13.8 & \\
\hline $\mathrm{S}$ & $\begin{array}{l}\text { I tend to keep what I am learning separate from my background } \\
\text { and experiences }\end{array}$ & 4.8 & \\
\hline S & I find that I am easily distracted & 11.0 & \\
\hline $\mathrm{D}$ & I frequently question ideas that are presented & 7.6 & $\stackrel{\tilde{\Xi}}{0}$ \\
\hline $\mathrm{D}$ & I try to make connections between ideas & 8.3 & $\stackrel{2}{2}$ \\
\hline $\mathrm{D}$ & Where possible I draw upon my own knowledge and background & 9.7 & $\stackrel{\infty}{\Xi}$ \\
\hline $\mathrm{D}$ & Evaluating what I have been told is important & 7.6 & 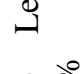 \\
\hline $\mathrm{D}$ & $\begin{array}{l}\text { I form my own ideas about the concepts presented using a } \\
\text { reasoned approach. }\end{array}$ & 8.3 & $\stackrel{\bar{D}}{\dot{\nabla}}$ \\
\hline
\end{tabular}

Table 1 -\% of respondents that identified their approach to studying (i.e. those strategies which are commonly associated with academic engagement). (S-Surface Learning; D - Deep Learning) 


\section{Age Differences}

When the same results were filtered for mature students (aged 21 and over) and those under 21, there appeared to be a marked contrast between the approaches to studying for both groups. It appears that mature students prefer approaches to studying that are aligned with surface learning (63\%), whereas students aged below 21 show equal preferences for engaged/disengaged learning strategies.

\section{Knowing students}

Assessing the results to consider how well students' knew their lecturers indicated that students who felt that their lecturers knew them were more likely to engage in study approaches that reflected deep learning (67\%). Whereas those respondents who indicated that academic staff do not know them sufficiently well, or at all, indicated a preference for learning approaches that are more commonly associated with surface learning.

\section{Attendance at lectures}

The analyses were repeated to compare the frequency of attendance at lectures, but the data suggests that the pattern of attendance did not affect the propensity to adopt any particular learning approach. The reasons for attendance patterns were many and varied from, "It adds to my assessment and makes me understand the course better" to "Found I was more productive working at home on my own equipment".

\section{Conclusion}

This pilot study, which used a combination of qualitative and quantitative methods for enquiry, undertook to investigate whether academics can or do consider student diversity when they teach large cohorts of students in a single group. Unfortunately, the response to one of the research instruments, the student questionnaire, was limited and therefore the findings should be regarded with caution. It is felt that the poor response rate was most likely due to the timing of the study as participants were asked to complete the survey after they had begun their summer break and therefore reliance was upon them checking their university email accounts.

Despite the warning to view the findings of this research with caution, the data has highlighted some interesting characteristics that are worthy of further consideration. Analysing the results of respondents who indicate that they knew their tutors well indicated a preference for study approaches that are likely to develop deeper learning. Hockings, et al $(2010,107)$ also recognise the growing diversity of students and comment that there is now, "less opportunity to get to know ... students", with this in mind they stress the need to encourage "student-centred pedagogies" for "a deep approach to learning".

Interestingly, students who skip classes are not necessarily less engaged with their studies than their peers who attend sessions more frequently. From statements that respondents left in the questionnaire, these students appear to adopt approaches of their own that aid to deepen their understanding. The approaches that they described are recognised as student-centred learning (SCL) strategies. A particularly interesting facet that the student questionnaire highlighted was that mature students appear to prefer learning and teaching methods that are associated with surface learning, but as discussed in the literature review of this paper this may be culturally mediated and be a result of "their conceptions of themselves as learners" (Richardson 2005, 675).

As class sizes have become larger, it is clear that staff recognise the increased diversity of students. Many of the learning strategies that the teachers have adopted 
for their lectures are interactive and include a mix of traditional staff to student transmission coupled with methods, such as buzz groups, in which students are encouraged to question and evaluate ideas that are presented. Such approaches, which put "reliance upon active rather than passive learning" (Lea, et al 2003, 321) are believed to foster deeper engagement with learning (Hockings et al 2010, 96). Whether the teaching of large numbers of undergraduates in a single group can be genuinely inclusive is not simply a function of the learning and teaching strategies adopted but is also related to other factors including how well staff are able to get to know their students.

As a pilot study, this project has identified two areas for future investigation. With a predicted fall in traditional student numbers due to a reducing population of 18 year olds, the proportion of mature students entering HE will increase. If this suggestion becomes a reality, then university teachers will need to explore learning and teaching practices that are more adept to the needs of this changing demographic. The study also suggests that when lecturers know their students well, or by as much as the student feels is necessary, students are more likely to adopt a deeper approach to learning. This proposition plainly merits more research to explore its generalisability.

\section{Acknowledgments}

I wish to express my gratitude for comments on an early draft of this paper by Sheila Trahar and Sue Timmis as well as for the assistance of students and staff of the BSc Computing framework at Midway University.

\section{References}

Agnew, C and L.Elton. 1998. Lecturing in Geography, Cheltenham: Geography Discipline Network.

Belson, W. A. 1986. Validity in Survey Research, Aldershot: Gower

Bowl, M., Cooke, S., and Hockings, C. 2008. Home and away? Issues of student 'choice', living arrangements and what it means to be a student. Widening participation and lifelong learning, 10, no. 1: 4-13.

Brown, R. 2000. Diversity in higher education: do we really want it?, Perspectives, 4, no. $1: 2-6$

Bush, T. 2007. Authenticity in research - reliability, validity and triangulation. In Research Methods in Educational Leadership and Management, ed. A. R. J. Briggs and M. Coleman, London: Sage.

Cohen, L., L. Manion and K. Morrison. 2007. Research Methods in Education, 6th ed. London: Routledge

Colley, H., James, D., Tedder, M. and Diment, K. 2003. Learning as becoming in vocational education and training: class, gender and role of vocational habitus. Journal of Vocational Education and Training, 55, no. 4: 471-496.

Grace, S. and P. Gravestock. 2009. Inclusion and diversity: meeting the needs of all students, New York : Routledge

Hockings, C., S. Cooke and M. Bowl. 2010. Section 1 - Learning and teaching in two universities within the context of increasing student diversity: complexities, contradictions and challenges. In Improving Learning by Widening Participation in Higher Education ed. M. E. David. London: Routledge 
Lea, S. J., Stephenson, D. and Troy, J. 2003. Higher Education Students' Attitudes to Student-centred Learning: beyond 'educational bulimia'?, Studies in Higher Education, 28, no. 3: 321-334

Marton, F and R. Säljö. 1984. Approaches to learning, in F. Marton, D. Hounsell, and N. Entwistle. ed The Experience of learning, 36 - 55, Edinburgh: Scottish Academic Press

Meek, V. L., Goedegebuure, L and Huisman, J. 2000. Understanding Diversity and Differentiation in Higher Education: an Overview, Higher Education Policy, 13 no. $1: 1-6$

Neumann, R., Parry, S. and Becher, T. 2002. Teaching and learning in their disciplinary contexts: A conceptual analysis, Studies in Higher Education, 27: 405-417

Norton, L., Richardson, J. T. E., Hartley, J., Newstead, S and Mayes, J. 2005. Teachers' beliefs and intentions concerning teaching in higher education, Higher Education, 50: 537-571

Ramburuth, P. 2001. Cross Cultural Learning Behaviour in Higher Education: Perceptions versus Practice, ultiBase Articles

Richardson, J. 2005. Students' Approaches to Learning and Teachers' Approaches to Teaching in Higher Education, Educational Psychology, 25, no. 6: 673-680

Thomas, S.M, Smees, R, MacBeath, J and Robertson, P. 2000. Valuing Pupils Views in Scottish Schools, Educational Research \& Evaluation, 6 no. 4: 281-316

Trigwell, K., Prosser, M. and Waterhouse, F. 1999. Relations between teachers' approaches to teaching and students' approaches to learning, Higher Education, 37: 57-70

Trow, M. 1995. Diversity in higher education in the United States of America. Paper presented at the CVCP Seminar on Diversity in Higher Education, September $14-15$, in London, 